\title{
JOSEFO EXEGETA: HISTÓRIA E MEMÓRIA
}

\author{
Alex Degan* \\ Doutorando em História Social pela Universidade de São Paulo (USP) \\ Professor de História Antiga e Medieval da Pontifícia \\ Universidade Católica de Campinas (Puccamp).
}

\section{Resumo}

O presente artigo pretende propor uma leitura das obras do historiador Flávio Josefo ressaltando suas ligações com as tradições grega e judaica nos domínios da memória coletiva e da história clássica.

\section{Pallavras-chave}

Flávio Josefo $\bullet$ história $\bullet$ memória $\bullet$ judeus.

\section{Abstract}

The objective of this article is to propose an interpretation concerning the works of the historian Flavius Josephus, emphasizing his connections with Greek and Jewish traditions, with especial attention to the spheres of collective memory and classical history.

\section{Keywords}

Flavius Josephus $\bullet$ history $\bullet$ memory $\bullet$ Jews.

* Mestre em História econômica e bacharel em História pela FFLCH da USP, orientador: prof. dr. Norberto Luiz Guarinello; membro do Laboratório de Estudos sobre o Império Romano (LEIR). 
"Memória é o segredo da redenção."

Israel Baal Shem Tov

"Eu tinha coisas a dizer, mas não as palavras para dizê-las."

Elie Wiesel

\section{A problemática da memória e Flávio Josefo}

Uma rápida pesquisa acerca dos temas mais frequentados por pesquisadores contemporâneos nos apontará que entre eles a "problemática da memória vem se transformando em foco privilegiado de atenção"1. Muitas ciências se dedicam a estudar aspectos da memória, presentes em disciplinas tão complexas e particulares como a neurofisiologia, a psiquiatria, a informática aplicada à gestão de informação, a antropologia, a sociologia, a geografia, a história, a linguística, a filosofia e a psicologia social. A memória está em voga não só entre os especialistas, visto que reivindicações de resgate, preservação e conservação se consolidam na agenda política de estados e instituições, como também de grupos sociais organizados, partidos políticos, sindicatos de trabalhadores, minorias e grupos marginalizados. Apesar de tamanho crescimento e pluralidade de estudos, a memória levanta um universo de problemas ainda não explorados a contento. Se nos ativermos apenas ao ângulo da história observamos a profundidade dos temas que ainda não gozam de reflexões consolidadas. De fato, estamos apenas iniciando investigações de assuntos e temáticas importantes como os "revisionismos" na história, ${ }^{2}$ as questões ligadas à amnésia social, o campo da apropriação da memória alheia, a memória nacional e os problemas levantados entre a narrativa histórica e a memória. Em outras palavras, parte da historiografia contemporânea aponta para a investigação não apenas das teorias sobre a memória, mas, sobretudo, para o entendimento das "práticas e representações mnemônicas e rememorativas das sociedades e grupos". 3

\footnotetext{
${ }^{1}$ MENESES, Ulpiano Toledo Bezerra de. A crise da memória, história e documento: reflexões para um tempo de transformações. In: SILVA, Zélia Lopes da (org.). Arquivos, patrimônio e memória. São Paulo: Editora da Unesp / Fapesp, 1999, p. 11.

${ }^{2}$ VIDAL-NAQUET, Pierre. Os assassinos da memória: "Um Eichmann de papel” e outros ensaios sobre o revisionismo. Campinas: Papirus, 1988. p. 29-46.

${ }^{3}$ MENESES, op. cit., p. 11-13.
} 
Entre as primeiras grandes civilizações urbanas do sul da Mesopotâmia, o aparecimento da escrita ligava-se intimamente à justificação do poder monárquico, produzindo extensas listas de reis em que se contava como a realeza descendeu dos céus, encontrando sua legitimidade. Assim, o mito se fundia com a história, completando a genealogia do Estado. Na Grécia, a importância da memória era grande, tanto que se verificou a sua sacralização na figura de Mnemosýne, a deusa titã, mãe das musas e que personificava a lembrança. Tradicionalmente esta deusa presidia a função poética, inspirando o poeta-cantor (aedo) em atividades e vivências de revelações que escapavam aos olhos humanos. Inspirado por Mnemosýne e pelas musas, um aedo bem treinado cantava as genealogias de uma sociedade de tradição oral, organizando verdadeiros "arquivos orais" que visavam ordenar o mundo dos deuses e heróis. Percebe-se, nos exemplos, antigas e constantes ações da memória, valorizada como imprescindível à coesão dos laços sociais, ou seja, como um dos suportes essenciais para o encontrar-se dos sujeitos coletivos (estados, casas de nobres, aristocracias guerreiras, identidades étnicas e religiosas). Além de sua orientação aos sujeitos coletivos, a memória tem em seu cerne a função social de comunicar a outras pessoas informações e impressões ocorridas no passado e que não estão no presente em sua forma original. ${ }^{4}$ Assim, embora toda atividade mnemônica produza uma sensação de passado, ela está fincada em uma dinâmica social presente que, portanto, evidencia que o passado não é seu produtor ou detentor. A constituição da memória se dá no presente que incentiva, provoca e prescreve sua rememoração, oferecendo as condições necessárias para a formação de um campo fértil para a memória florescer.

Neste contexto, as investigações históricas podem se enriquecer ao reconhecer a memória como fornecedora de quadros de orientação, de assimilação do novo, de códigos para classificação e para o intercâmbio entre grupos, ${ }^{5}$ transformando-se em um importante objeto para a produção de conhecimento. Enquanto produto social, a memória se cristaliza em um conjunto de elementos necessários para a formação, manutenção e modificação das identidades individual, coletiva e nacional. Desenvolve uma complexa relação com a história científica, pois ao mesmo tempo em que serve de repertório para os estudos dos

\footnotetext{
${ }^{4}$ LE GOFF, Jacques. História e memória. Campinas: Editora da Unicamp, 2003, p. 420-421.

${ }^{5}$ MENESES, Ulpiano Toledo Bezerra de. A história, cativa da memória?. Revista do Instituto de Estudos Brasileiros. São Paulo, 34, 1992, p. 12.
} 
historiadores e que é fertilizada e renovada pelas pesquisas acadêmicas, é alvo da crítica historiográfica, que volta contra a memória "todo seu peso disciplinar". ${ }^{6}$ Fundamenta-se todo um campo de investigações dentro das ciências sociais que explicitam aquilo que Ulpiano Meneses qualificou como "economia política da memória". ${ }^{7} \mathrm{O}$ crescimento desta direção das pesquisas deve ser creditado ao sociólogo Maurice Halbwachs, que observou que, no ato de lembrar e de rememorar, nos servimos de campos de significados (les cadres sociaux) que funcionam como pontos de referência. Estes quadros sociais da memória se estruturam sobre noções de tempo e de espaço (de uma percepção histórica) que lhe são fundamentais para a rememoração do passado "na medida em que as localizações espacial e temporal das lembranças são a essência da memória". ${ }^{8}$

Aqui nos aproximamos de nosso objeto, orientado para a análise e investigação das relações entre memória e história enquanto prática social e narrativa que produz uma noção de tempo na qual se associam o rememorar, o reinventar e o selecionar. Para tanto, propomos desenvolver uma leitura do historiador Flávio Josefo, autor de uma importante obra produzida no século I e aceito como o primeiro grande historiador dos judeus. Neste sentido, desejamos observar sua narrativa do passado, atento para os mecanismos e formas que Josefo lançou mão para operar a riquíssima tradição judaica, construindo uma interpretação do judaísmo 9 na evolução de suas obras e vida. Josefo contou uma história fundamental para sua etnia que foi profundamente vivida e sofrida por ele. Os traumas da destruição de Jerusalém e da desorganização da sociedade hebraica palestina impulsionaram as comunidades judaicas na busca a outras possibilidades de adaptação, enfrentamento e sobrevivência dentro do Mediterrâneo romano. De certa forma, podemos afirmar que a religião judaica moderna começou a se estruturar em decorrência dos acontecimentos gerados pelo levante de 66/70. Com a destruição do templo, o fim dos sacrifícios e dos serviços sacerdotais, os movimentos rabínicos, com destaque para o grupo de Rabi Yochanan ben Zakai, iniciaram a resolução dos impasses provocados pela derrota, re-intre-

\footnotetext{
${ }^{6}$ GUARINELLO, Norberto Luiz. História científica e memória coletiva. Revista Brasileira de História. São Paulo, v. 7, nº 13, 1994, p. 181.

${ }^{7}$ MENESES, Ulpiano Toledo Bezerra de. A crise da memória, história e documento: reflexões para um tempo de transformações. In: SILVA, Zélia Lopes da (org.). Arquivos, patrimônio e memória. São Paulo: Editora da Unesp / Fapesp, 1999, p. 12.

${ }^{8}$ FÉLIX, Loiva Otero. História e memória: a problemática da pesquisa. Passo Fundo: UPF Editora, 2004, p. 38.

${ }^{9}$ Entendemos judaísmo como a religião e o modo de vida tradicional dos judeus.
} 
pretando e re-fazendo o judaísmo, mas dentro de limites estabelecidos pela tradição. Acreditamos que Josefo trabalhou motivado pelos mesmos impasses.

Quando ele se colocou no exercício de redigir a história de seu povo, começando pela guerra que destruiu a Palestina judaica, escreveu assistido por lembranças de velhos lugares que não existiam mais: foram arrancados seus espaços naturais, como o templo que legitimava sua casta sacerdotal, assim como a estrutura urbana da velha Jerusalém. E neste lembrar de um tempo passado e de um lugar desalojado, mas ainda intimamente presentes, Flávio Josefo iniciou sua importante obra inscrita em um refazer, numa complexa reflexão que mobilizou um grande trabalho intelectual e sentimental, distante da fria repetição e retificação do passado. Assim como ocorreu com o grupo de Rabi Yochanan ben Zakai, Josefo se encontrou com a difícil tarefa de produzir um "acerto de contas" entre o passado, o presente e o futuro do seu judaísmo, expresso em suas diferentes obras. De imediato nos interessa refletir acerca da trajetória de Josefo, assim como observar as circunstâncias e características específicas de cada uma de suas obras.

Entendemos que elas, de forma geral, se equilibram em duas direções. ${ }^{10}$ Suas obras iniciais, A guerra judaica ${ }^{11}$ e Antiguidades judaicas, ${ }^{12}$ manifestaram sua ambição em ser um historiador que respondia aos modelos clássicos, assim como representaram uma vontade de restituir um lugar honrado aos seus compatriotas, visto que narrava a história de uma grande guerra e de uma antiga etnia. ${ }^{13}$ Seus derradeiros escritos são mais complexos e contraditórios. Contra Apião ${ }^{14}$ apresenta-se muito mais militante que seus textos anteriores, abordando a originalidade da Lei judaica e o seu judaísmo em detalhes empolgantes. Autobiografia, ${ }^{15}$

${ }^{10}$ LAMOUR, Denis. Flávio Josefo. São Paulo: Estação Liberdade, 2006, p. 103.

${ }^{11}$ Primeiro trabalho escrito por Josefo que, provavelmente, iniciou suas notas ainda na condição de cativo. Embora ele nos diga que trabalhou em outra versão, escrita em aramaico, o texto que chegou até nós foi registrado em língua grega. Estima-se que a edição grega tenha aparecido no final do reinado de Vespasiano, entre 75 e 79.

${ }^{12}$ Obra extensa, composta por 20 tomos, que trata desde as origens do povo hebreu até o início do levante de 66-70. Sua publicação se deu em torno de 94 e 99.

${ }^{13}$ Josefo reproduz com adaptações o preâmbulo de Tucídides, destacando o princípio axiológico (a questão da grandeza) de sua narrativa. Para um estudo atento a esta questão dentro da obra de Tucídides, ver MURARI PIRES, 1999, p. 151-180.

${ }^{14}$ Obra que faz uma apologia do judaísmo. Escrita como resposta às críticas de intelectuais helenistas que questionavam a antiguidade dos judeus, procurando responder a calúnias e acusações antissemitas, provavelmente foi publicada posteriormente aos textos do Bellum judaicum e Antiguidades judaicas (entre 94 e 99).

${ }^{15}$ Aparece como um apêndice, talvez sendo acrescentado em alguma outra edição de suas obras posteriores. Publicada em 94 e 100. 
seu livro mais controverso e depreciado, separa-se ainda mais de seus escritos "históricos": mal escrita e repleta de contradições (em comparação com seus escritos anteriores), esta obra oferece grandes possibilidades para refletirmos sobre as lembranças de Josefo, assim como seus ressentimentos e compromissos, todos imbricados em sua tarefa de lembrar, escrever e narrar. As obras de Flávio Josefo, neste sentido, oferecem uma grande oportunidade para refletirmos os desafios vividos pelos judeus do século I, ponderarmos sobre as relações entre o centro do poder político (Roma) e suas periferias (os judeus palestinos e da diáspora), como também investigar o re-fazer da memória em um autor particular, tendo a oportunidade de observá-lo em quatro obras impressionantes.

\section{Homem intermediário}

Em um texto publicado em 1967, o filósofo argelino Jacques Derrida colocou uma inquietante pergunta: "Somos judeus? Somos gregos? Nós vivemos na diferença entre o judeu e o grego, que talvez seja a unidade daquilo que chamamos história". ${ }^{16}$ Cerca de duas décadas antes, o pensador alemão Erich Auerbach, ponderando sobre a representação literária da realidade na cultura europeia, compara dois estilos fundadores e diferentes, o de Homero e o do Antigo Testamento. Em suas palavras:

Os dois estilos representam, na sua oposição, tipos básicos: por um lado [na tradição homérica], descrição modeladora, iluminação uniforme, ligação sem interstícios, locução livre, predominância do primeiro plano, univocidade, limitação quanto ao desenvolvimento histórico e quanto ao humanamente problemático; por outro lado [na tradição do Antigo Testamento], realce de certas partes e escurecimento de outras, falta de conexão, efeito sugestivo do tácito, multiplicidade de planos, multivocidade e necessidade de interpretação, pretensão à universalidade histórica, desenvolvimento da apresentação do devir histórico e aprofundamento do problemático. ${ }^{17}$

O que aproxima Derrida e Auerbach é que ambos reconheceram a fundamental importância das culturas helênica e hebraica para a formação da civilização ocidental, nos auxiliando a problematizar o mesmo fundamento híbrido presente na obra do historiador Flávio Josefo.

\footnotetext{
${ }^{16}$ DERRIDA, Jacques. L'Écriture et la différence. Paris: Seuil, 1967, p 227.

${ }^{17}$ AUERBACH, Erich. Mimesis. São Paulo: Perspectiva, 2004, p. 20.
} 
Quando observamos a literatura que trata do autor, revela-se claro que assim como foi controversa sua vida, igualmente polêmica foi sua obra, marcada por uma espécie de dupla cidadania judaica e romano-helenística. O historiador francês Pierre Vidal-Naquet formulou uma interessante interpretação, ${ }^{18}$ apresentando o autor como um verdadeiro homem intermediário, que dialogou nas duas culturas, oferecendo um campo de visão dentro de outro campo, mostrando, no discurso romano da guerra, seu orgulho de ser judeu. O próprio nome que a tradição lhe consagrou, Flavius Josephus, é híbrido, unindo seu nome hebreu latinizado com a gens de Vespasiano, funcionando como um "cartão de visita" de uma obra que também se equilibrou e misturou tradições.

Como podemos avaliar as contribuições das obras de Josefo dentro da historiografia clássica da segunda metade do século I? Realizou uma obra com vistas ao público greco-romano ou almejou alcançar os judeus da diáspora e do Oriente? Após uma primeira versão aramaica da Guerra judaica, destinada aos judeus partos (Guerra, I: 3-6), Josefo escreveu em grego, expressando um desejo de se vincular com a cultura helenística de seus leitores. Antes de seus escritos, os judeus experimentaram outros dois intentos grandiosos para se aproximarem das culturas helenística e romana. A primeira tentativa se deu com a Septuaginta (LXX), um colossal esforço judaico em traduzir os textos sagrados para o grego, que, embora estivesse direcionada aos judeus de Alexandria, ${ }^{19}$ poderia despertar a atenção de algum grego curioso. $\mathrm{O}$ segundo intento de relacionamento se encontra nos textos de Filo, que utilizou do método alegórico na tentativa de conciliar os pensamentos hebreu e helênico. Ambos os predecessores de Josefo fracassaram em despertar a intelligentsia pagã e, a despeito de seu esforço em escrever em grego, a recepção aos seus textos também não empolgou seus contemporâneos. Podemos supor um sucesso posterior, entre os cristãos, visto a existência das cópias produzidas na Idade Média. ${ }^{20}$ Todavia, o silêncio dos textos romanos do período em relação aos seus escritos sugere que ele teria sido ignorado como autor da tradição grego-romana.

\footnotetext{
18 "Un intermediario offre scarso interesse quando si limita a essere il rappresentante d'un campo in seno a un altro campo; e Giuseppe difendeva di fronte agli ebrei la causa dei suoi padrón romani. Ma a uma seconda lettura, il discorso indirizzato ai romani attesta l'immenso orgoglio che Giuseppe annetteva al fatto d'essere ebreo". VIDAL-NAQUET, Pierre. Il buon uso del tradimento: Flavio Guiseppe e la guerra guidaica. Roma: Editori Riuniti, 1980, p. 32.

${ }^{19}$ MOMIGLIANO, Arnaldo. Os limites da helenização. Rio de Janeiro: Zahar, 1991, p. 84.

${ }^{20}$ HADAS-LEBES, Mireille. Flávio Josefo. O judeu de Roma. Rio de Janeiro: Imago, 1991, p. 268.
} 
Ainda assim, Josefo desejou escrever em grego para um público helenizado e dentro de um gênero literário específico: a história. Podemos identificar em suas obras estreitos usos de estruturas comuns na historiografia greco-romana, como a busca pela verdade, ${ }^{21}$ a censura aos autores anteriores que produziram visões parciais ${ }^{22}$ e a utilização de discursos intercalados com a narrativa. ${ }^{23} \mathrm{Com}$ Tucídides, Josefo aprendeu a articular uma narrativa política, buscar as causas profundas dos acontecimentos e, como estudou Martin Goodman, ${ }^{24}$ a ideia grega de stasis, a falta de harmonia e coesão social como germe de uma revolta. Outro grego, Políbio, também pode ser apontado como inspirador. Ambos se encontraram na condição de cativos de uma Roma vencedora, igualmente motivados no entendimento das razões dos êxitos latinos. Outro historiador grego identificado em suas obras foi Dionísio de Halicarnasso. ${ }^{25}$ Autores de obras que desejavam uma história total de seus objetos, Dionísio e Josefo também se aproximavam na tentativa de entender a situação de suas etnicidades frente aos vitoriosos romanos. O grego Dionísio retirou de Roma qualquer denominação bárbara, estreitando suas tradições com as helênicas; sua Roma vencedora seria uma continuação da história gloriosa da Grécia. Em Josefo, os romanos também eram dignos, mas não porque eram herdeiros legítimos da epopeia judaica, e sim pelas falhas dos judeus. Em decorrência de suas próprias fraquezas e faltas, os judeus foram punidos por YHWH com a conquista romana. Frente a isto, Roma se tornou digna de figurar na história judaica.

21 "Josephus shares the theories of his fellow historians concerning impartiality and passion for truth. Like them, he often criticizes other historians who frequently violate this ideal”. BILDE, Per. Flavius Josephus between Jerusalem and Rome. Journal for the Study of the Pseudepigrapha Supplement, 1988, p. 203.

${ }^{22}$ HADAS-LEBES, Mireille. Flávio Josefo. O judeu de Roma. Rio de Janeiro, op. cit., p. 238.

23 "Above all, it is the speeches ascribed to protagonists in the history which allow an ancient author to comment personally on events. Even so austere a writer as Thucydides, whatever his professed intentions were, used speeches not so much to report, or even to try to reconstruct what was actually said on specific occasions, as to present analyses of different political positions, and to generalize about human affairs. In principle, what Josephus does is no different - the speeches are a vehicle for his thoughts". RAJAK, Tessa. Josephus: the historian and his society. London: Duckwoth, 1983, p. 80.

24 "A melhor injúria é colhida no vocabulário político grego, e especificamente no de Tucídides, e não na própria imaginação de Josefo: a stasis foi causada por tiranos revolucionários cuja brutalidade para com seus compatriotas e autoimposição a uma população relutante são constantemente enfatizadas". GOODMAN, Martim. A classe dirigente da Judeia: As origens da revolta judaica contra Roma. Rio de Janeiro: Imago, 1994, p. 202.

${ }^{25}$ THACKERAY, Henry St. John. Flavius Josèphe: 1'homme et l'historien. Paris: Les Éditions du Cerf, 2000, p. 36-37. 
Escrita em grego e com profundas relações com a produção histórica de sua época, Flávio Josefo pode ser lido como mais um nome da historiografia greco-romana. Mas se isto não é feito, ou quando é, são tomadas ressalvas, o que separa Josefo de seus modelos gregos? A diferença encontra-se na seguinte observação: enquanto seus colegas gregos tinham que se preocupar em fazer um relato político que atendesse aos seus conterrâneos e ao entendimento helênico, Flávio Josefo também tinha que se ocupar de Deus. Pois não era YHWH o dono dos destinos de seu povo escolhido?

\section{Josefo exegeta}

Indo além de seus modelos helênicos, seus atributos enquanto historiador reuniam também as ocupações de sacerdote e profeta. Foram com estas habilidades, fortes na tradição judaica, que Josefo conseguiu ver pelo curso da história, equacionando os eventos narrados com a presença absoluta de YHWH, o separando dos gregos. Além disso, ele se via dentro de uma tradição, tão legítima para seu povo quanto a da história para os helenos: a tradição dos profetas. Anotou, em duas oportunidades, que em Israel eram os profetas que registravam a história, afirmando o desejo de continuar o trabalho do ponto em que eles pararam. ${ }^{26}$

Para o historiador contemporâneo Yosef Hayim Yerushalmi, esta forma como Josefo encara seu ofício e a história pode ser expandida ao pensamento judaico antigo. Em suas palavras:

Se Heródoto foi o pai da história, os pais do significado na história foram os judeus. $\mathrm{O}$ antigo Israel foi quem primeiro determinou um significado decisivo à história. Repentinamente, por assim dizer, o encontro crucial entre o homem e o divino deslocou-se do reino da natureza e do cosmo para o plano da história, concebida agora em termos do desafio divino a da resposta humana. O conflito pagão dos deuses com as forças do caos ou com outra qualquer foi substituído por um drama de ordem diferente e mais penetrante: a luta paradoxal, no curso da história, entre a vontade divina de um Criador onipotente e o livrearbítrio de sua criação, o homem; uma dialética tensa de obediência e rebeldia. ${ }^{27}$

${ }^{26}$ Guerra, I: 8. "Fixarei, para tanto, o início de minha obra no lugar em que terminam os testemunhos dos historiadores e de nossos profetas". Autobiografia, VI: 29. "Tentarei expor brevemente que nossos antepassados tiveram o mesmo cuidado acerca dos anais [...], reservando esta atividade aos sumos sacerdotes e aos profetas".

${ }^{27}$ YERUSHALMI, Yosef Hayim. Zakhor: história judaica e memória judaica. Rio de Janeiro: 
A nosso ver, a obra de Josefo assumiu compromissos na tentativa de assimilar o trauma judaico que se seguiu após 70 , operando nesta dialética tensa. Com o templo incendiado e a cidade de Jerusalém destruída, o judaísmo palestino sofreu um duríssimo golpe. Na esteira, o cânon da Bíblia hebraica (Tanach) foi profundamente estudado, a Mischná e o Midrash Halachá iniciaram seus processos de redação e edição, a comunidade farisaica sobrevivente em Yavné deu início à hegemonia rabínica ${ }^{28}$ e o cristianismo começou, de fato, a se dissociar do universo judeu. Os dois primeiros séculos da Era Comum formam um período de furiosa atividade literária. A religião e as tradições mosaicas não congelaram com a queda do templo e, neste ambiente de profunda desolação, os judeus, tanto da Palestina quanto da Diáspora, se viram presos em uma grande tarefa de recriar dentro da tradição, trabalhando intensamente na resolução de seus impasses.

Com certeza, os aspectos vindouros do cristianismo e do judaísmo rabínico ajudam a entender o destaque que, em muitos estudos, produziu uma visão equivocada do momento, funcionando como uma teleologia retrospectiva ou uma previsão ao contrário: ${ }^{29}$ tradicionalmente o século I foi entendido com o peso da vitória cristã e rabínica, como se aquele passado já estivesse absolutamente preso e resignado aos acontecimentos futuros. Entretanto, poucos foram os pesquisadores que observaram as obras de Josefo dentro do mesmo contexto criador. Talvez estigmatizado pela traição ou pela fama de propagandista de Flávio, suas obras foram estudadas como importantes contribuições de um judeu helenizado, dono de um judaísmo frio, retórico e incolor que, segundo Momigliano, nunca soube da alegria de viver em comunidade. ${ }^{30}$ Seth Schwartz, que o censura por ser ignorante ou preguiçoso em suas leituras dos textos hebraicos, ${ }^{31}$ chega a

\footnotetext{
Imago, 1992, p. 28.

${ }^{28}$ NEUSNER, Jacob. First century judaism in crisis: Yohanan ben Zakkai and the renaissance of Torah. Nashville: Abingdon Press, 1975.

${ }^{29}$ CATROGA, Fernando. Memória, história e historiografia. Coimbra: Quarteto, 2001, p. 21.

30 “Josefo no sabe nada de la alegría de vivir dentro de la ley, el sentido de la vida disciplinada de la comunidad, la preocupación y el amor por las generaciones más jóvenes y la confianza en Dios". MOMIGLIANO, Arnaldo. De paganos, judios y cristianos. México: Fondo de Cultura Economica, 1992, p. 200.

31 'In another chronographic passage (BJ 6.269-70), however, he speaks of the 'first foundation' of the Temple by Solomon, its destruction by the Babylonians, and its reconstruction by Haggai in the second year of Cyrus. If these passages are derived from other chronographers, they show that Josephus was either too ignorant or too lazy to correct them; if they reflect his own memory of his biblical readings, they suggest that his reading was scanty and prove that his memory was muddled". SCHWARTZ, Seth. Josephus and judaean politics. New York: E. J. Brill, 1990, p. 174.
} 
reduzir seus escritos ao patamar de um travel book de uma região exótica do Império. ${ }^{32}$ Seus silêncios sobre a vida nas sinagogas, ${ }^{33}$ as articulações cristãs e suas confusões sobre os movimentos messiânicos ${ }^{34}$ reforçariam ainda mais sua característica problemática e pouco confiável. Nossa hipótese reconhece sua participação neste momento de intensas proposições ao futuro dos judeus como uma leitura legítima. Entendemos que, da mesma forma que Yochanan ben Zakai, ou Paulo de Tarso, Josefo possuiu uma genuína preocupação em ler e reler a tradição do judaísmo frente aos novos acontecimentos.

Visão próxima de nossos propósitos foi colocada por Norberto Luiz Guarinello, em um texto em que discutiu a experiência cotidiana do ponto de vista do historiador. ${ }^{35}$ Sua proposta não se limita ao entendimento do cotidiano enquanto universo da repetição e do não-acontecimento, mas sim enquanto um momento dado no tempo, um momento do acontecimento e do não-acontecimento. Assim, o cotidiano não deve ser encarado como uma esfera da vida alienada, "mas como um tempo, como um momento, um presente que, visto em perspectiva, congrega uma sucessão de presentes no fluxo contínuo da vida", ${ }^{36}$ atuando como um campo de restrições e possibilidades em aberto para projetos alternativos de futuro. Tal leitura nos oferece uma possibilidade ampla de analisar o século I, pois considera também as indeterminações, incertezas e possibilidades do momento.

Concordando com as afirmações de Guarinello, entendemos ser possível uma interpretação mais ampla de Josefo, de seus escritos e de suas relações com o século I. Ele também participou deste grande movimento de busca por resoluções dos problemas presentes, estruturando suas reflexões em diálogos entre o passado, o presente e o futuro, funcionando como âncora e plataforma. Enquanto âncora possibilitou que, diante do turbilhão de mudanças, seu judaísmo não se desmanchasse no ar. Enquanto plataforma permitiu que suas esperanças de sobrevivência se projetassem para o futuro com os pés solidamente plantados no passado criado, recriado ou inventado como tradição.

\footnotetext{
${ }^{32}$ SCHWARTZ, op. cit., p. 33.

${ }_{33}$ MOMIGLIANO, Arnaldo. De paganos, judios y cristianos. México: Fondo de Cultura Economica, 1992, p. 197.

${ }^{34}$ DOBRORUKA, Vicente. Josefo, a literatura apocalíptica e a Revolta de 70 na Judeia. Phoînix. Rio de Janeiro, $\mathrm{n}^{\circ}$ 8, 2002, p. 374.

${ }^{35}$ GUARINELLO, Norberto Luiz. História científica, história contemporânea e história cotidiana. Revista Brasileira de História. São Paulo, v. 24, n. 48, 2004, p. 13-38.

${ }^{36}$ GUARINELLO, op. cit., p. 25.
} 
O historiador canadense John van Seters, refletindo sobre o sentido de uma tradição, observa que:

A tradição é usada para fortalecer a crença, explicar ou atribuir significado à maneira de ser das coisas, dominar pessoas e instituições com autoridade, legitimar práticas, controlar o comportamento, criar a noção de identidade pessoal e coletiva e comunicar habilidades e conhecimento. O número de formas que a tradição verbal pode assumir - independente de ser poesia ou prosa; cantada, falada ou escrita - é quase infinito. ${ }^{37}$

Esta vocação para a explicação e para o sentimento de coletividade que as mais diversas formas de tradição podem comportar nos permite refletir sobre os valores da história e da memória enquanto participantes desses movimentos. Para Maurice Halbwachs, ${ }^{38}$ a memória coletiva representa o conjunto comum de memórias partilhadas por gerações subsequentes. Para ele, memória é o que uma cultura coletivamente carrega de seu passado, enquanto história envolve uma avaliação crítica do passado. Operando em um nível afetivo, a memória confirma similaridades entre o passado e o presente. A história, ao contrário, reconstrói o passado a partir de uma distância crítica e tenta transmitir o sentido de que suas conexões com o presente são desprovidas de compromisso emocional.

Concordamos com a distinção trabalhada por Halbwachs, mas entendemos que Josefo está implicado com as duas formas de ponderar sobre o passado. Uma vez em seu exílio em Roma, iniciou um projeto ambicioso, almejando aos judeus um lugar de destaque na história universal. Escreveu história dentro do gênero estabelecido pelos gregos e como uma "forma intelectual na qual uma civilização presta contas do seu passado a si própria", ${ }^{39}$ aprofundando reflexões provocadas pelos impasses vividos pelos judeus, em especial os palestinos. Em suma, quando observamos sua obra em conjunto, estamos diante de um trabalho mais ambicioso do que o repertório da história helênica poderia comportar. Era preciso escrever como um grego, mas pensar como um fariseu.

Neste processo de sobrevivência e adaptação, entendemos que o passado e a história dos judeus foram fundamentais para assegurar coesão da comunidade,

\footnotetext{
${ }^{37}$ VAN SETERS, John. Em busca da história: historiografia no mundo antigo e as origens da história bíblica. São Paulo: Edusp, 2008, p. 19.

${ }^{38}$ HALBWACHS, Maurice. Memória coletiva. São Paulo: Vértice, 1990, p. 80.

${ }^{39}$ HUIZINGA, 1963 apud VAN SETERS, 2008, p. 19.
} 
assim como também se tornaram o ponto sensível de sua religião. ${ }^{40}$ Esta memória operativa no judaísmo, fundamental para o reconhecimento do pacto e de YHWH, estrutura toda a fundação da identidade judaica, voltando-se e reiterando as ações de Abraão, de Moisés e dos profetas. Desempenha, nas palavras da psicóloga social Ecléa Bosi, uma evocação, "ao fazer cair a barreira que separa o presente do passado, lançando uma ponte entre o mundo dos vivos e o do além". ${ }^{41}$ Outra característica importante nas ações de recordação empreendidas pelos antigos judeus encontrava-se na vocação educacional que estas memórias traziam. A evocação do passado também ensinava com vistas para o presente e o futuro. Em Josefo tal preocupação foi recorrente, inclusive justificando seus trabalhos como conselhos que deveriam "consolar os vencidos e desencorajar outras tentativas de insurreição". ${ }^{42}$ Em outras palavras, para a tradição judaica na qual Josefo estruturou seus escritos, recordar o passado era, ao mesmo tempo, uma ação religiosa e um ato destinado a influenciar o presente, daí suas profundas lições, seus momentos de ensino. Tal característica, segundo Yerushalmi, ${ }^{43}$ estaria mais presente ainda em momentos de crise, já que na história judaica, particularmente durante os períodos bíblico e medieval, as recordações narrativas do passado foram inspiradas em grande parte por acontecimentos catastróficos.

Este padrão do movimento da história, lançado por YHWH, foi notado por Josefo que, como um novo Jeremias, se preocupou em identificar e denunciar as falhas dos judeus que provocaram a ira divina. Assim, não só as desgraças sofridas pelos judeus eram explicadas, como eram passíveis de entendimento

\footnotetext{
${ }^{40}$ Para Le Goff: "se a memória antiga foi fortemente penetrada pela religião, o judaico cristianismo acrescenta algo de diverso à relação entre memória e religião, entre o homem e Deus. Pode-se descrever o judaísmo e o cristianismo, religiões radicadas histórica e teologicamente na história, como religiões da recordação. E isto em diferentes aspectos: porque atos divinos de salvação situados no passado formam o conteúdo da fé e o objeto do culto, mas também porque o livro sagrado, por um lado, a tradição histórica, por outro, insistem, em alguns aspectos essenciais, na necessidade da lembrança como tarefa religiosa fundamental”. LE GOFF, op. cit., p. 438.

${ }^{41}$ BOSI, Ecléa. Memória e sociedade. São Paulo: Companhia das Letras, 1994, p. 59.

${ }^{42}$ Guerra, III: 108-109.

43 "Para rabinos, a Bíblia não era somente um repositório da história passada, mas revelava um padrão de toda a história, e eles haviam aprendido bem suas escrituras. Sabiam que a história tinha um propósito - o estabelecimento do reino de Deus na terra, e que o povo judeu tinha um papel central a desempenhar no processo. Estavam convencidos de que o pacto entre Deus e Israel era eterno, embora os judeus muitas vezes tenham se rebelado e sofrido as consequências. Acima de tudo, haviam aprendido na Bíblia que o verdadeiro ritmo da história frequentemente se dava abaixo de suas superfícies manifestas, uma história invisível mais real do que o mundo iludido pelos mais estridentes ritmos externos do poder poderia reconhecer". YERUSHALMI, Yosef Hayim. Zakhor: história judaica e memória judaica. Rio de Janeiro: Imago, 1992, p. 41.
} 
a supremacia romana e a sua entrada na história orquestrada pela divindade. Como Jeremias identificou em Nabucodonosor um instrumento divino necessário na punição dos judeus pecadores, Josefo seguiu o mesmo modelo. YHWH, por culpa dos judeus que cometeram abusos e ignoraram as chamadas para a concórdia, despejou uma beligerante Roma como castigo.

Esta proposta de leitura da história tornava possível a compreensão dos acontecimentos catastróficos, pois sua interpretação repousava na busca pelos significados e sentidos estabelecidos por YHWH. Mesmo os maiores infortúnios estariam dentro de uma perspectiva divina; caberia ao historiador/profeta ter atenção para com os acontecimentos do passado e do presente. Todavia, tal característica não implicava na recordação de tudo que aconteceu na história, pois existia um princípio único de seleção. Segundo Yerushalmi, "as respostas do homem [aos atos de intervenção sagrada na história], negativas ou positivas, estas sim, deveriam ser registradas". ${ }^{44}$ Em Josefo, este princípio fica evidente quando nos atentamos ao uso que ele faz da Septuaginta, com inúmeras referências ao seu conhecimento e à autoridade dos sábios que se empenharam em sua execução. Tal menção não é gratuita: assim como os setenta sábios produziram uma tradução iluminada da Bíblia hebraica, agora era Josefo quem desejava protagonizar uma atividade semelhante, buscando em sua interpretação da história judaica os momentos de intervenção divina, assim como as respostas dos homens. Toda a obra de Josefo refletiu este reconhecimento de que a sucessão dos acontecimentos históricos possui por determinante a conjunção da vontade dos homens e os desígnios de Deus. Aqui ele se separou decididamente de seus modelos clássicos, ou seja, se sua teoria foi helenizada na forma e apresentação, foi judaica na essência, pois aceitou a onipotência divina nos arranjos das nações, atento ao peso do julgamento de YHWH. Josefo foi um providencialista.

Por fim, Josefo também qualificou seu trabalho como a ação de um tradutor. Acreditamos que neste ato de "traduzir", o historiador judeu produziu uma obra que integrou lendas bíblicas com acontecimentos presentes, fundindo a tradição judaica com a historiografia greco-romana em um momento de crise, no qual sua própria sobrevivência e de sua cultura estiveram ameaçadas. Por exemplo, mesmo seguindo com respeito Tucídides, não se ergueu uma distinção clara entre uma idade mítica e uma idade histórica (observação acentuada quando Josefo escreveu sobre a longevidade dos patriarcas), e o lugar de YHWH per-

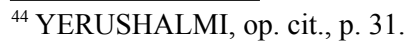


maneceu intocável (o que refletia o encontro entre o humano e o divino que se desenvolveu no plano da história judaica, não grega).

Assim, observando a leitura que Josefo constrói do judaísmo, consciente de seus compromissos e indefinições, pretendemos ressaltar outra maneira de se perceber o momento e de se projetar o futuro, maneira que não conseguiu permanecer nas tradições rabínicas e cristãs, não ao menos de forma expressiva. Sua leitura do judaísmo em muito se extinguiu. Contudo, Josefo, com sua interpretação de um judaísmo do templo, do sacerdócio e da restauração de uma aristocracia nativa em Jerusalém, manifestou uma possibilidade que, mesmo fracassada, existiu entre os círculos judaicos pós derrota. Seu entendimento possibilita, então, uma leitura mais justa e abrangente das mudanças vividas pelas comunidades judaicas e cristãs primitivas entre os séculos I e II. Nem tão messiânicos, nem tão farisaicos: Josefo nos obriga a utilizar o plural para pensar o judaísmo.

\section{Referências bibliográficas}

\section{Fontes}

JOSEPHUS. The Jewish war. London: Harvard University Press (Loeb Classical Library), 1989.

JOSEPHUS. The life. Against Apion. London: Harvard University Press (Loeb Classical Library), 1997.

JOSEPHUS. Jewish antiquites. London: Harvard University Press (Loeb Classical Library), 1970.

\section{Livros e artigos}

AUERBACH, Erich. Mimesis. São Paulo: Perspectiva, 2004.

BILDE, Per. Flavius Josephus between Jerusalem and Rome. Journal for the Study of the Pseudepigrapha Supplement Series 2, 1988.

BOSI, Ecléa. Memória e sociedade. Lembranças de velhos. São Paulo: Companhia das Letras, 1994.

CATROGA, Fernando. Memória, história e historiografia. Coimbra: Quarteto, 2001.

DERRIDA, Jacques. L'Écriture et la différence. Paris: Seuil, 1967.

DOBRORUKA, Vicente. Josefo, a literatura apocalíptica e a Revolta de 70 na Judeia. Phoînix. Rio de Janeiro, no 8, 2002, p. 372/391.

FÉLIX, Loiva Otero. História e memória: a problemática da pesquisa. Passo Fundo: UPF Editora, 2004.

GOODMAN, Martim. A classe dirigente da Judeia. As origens da revolta judaica contra Roma. 66-77 d.C. Rio de Janeiro: Imago, 1994. 
GUARINELLO, Norberto Luiz. História científica, história contemporânea e história cotidiana. Revista Brasileira de História. São Paulo, v. 24, nº 48, 2004, p. 13-38.

GUARINELLO, Norberto Luiz. História científica e memória coletiva. Revista Brasileira de História. São Paulo, v. 7, n. 13, 1994, p. 49-62.

HALBWACHS, Maurice. Memória coletiva. São Paulo: Vértice, 1990.

HADAS-LEBES, Mireille. Flávio Josefo. O judeu de Roma. Rio de Janeiro: Imago, 1991.

LAMOUR, Denis. Flávio Josefo. São Paulo: Estação Liberdade, 2006.

LE GOFF, Jacques. História e memória. Campinas: Ed. da Unicamp, 2003.

MENESES, Ulpiano Toledo Bezerra de. A história, cativa da memória?. Revista do Instituto de Estudos Brasileiros. São Paulo, 34, 1992, p. 9-24.

MENESES, Ulpiano Toledo Bezerra de. A crise da memória, história e documento: reflexões para um tempo de transformações. In: SILVA, Zélia Lopes da (org.). Arquivos, patrimônio e memória. São Paulo: Editora da Unesp / Fapesp, 1999.

MOMIGLIANO, Arnaldo. Os limites da helenização. Rio de Janeiro: Jorge Zahar, 1991.

MOMIGLIANO, Arnaldo. De paganos, judios y cristianos. México: Fondo de Cultura Economica, 1992.

MURARI PIRES, Francisco. Mithistória. São Paulo: Humanitas / Fapesp, 1999.

NEUSNER, Jacob. First century judaism in crisis: Yohanan Ben Zakkai and the renaissance of Torah. Nashiville: Abingdon Press, 1975.

RAJAK, Tessa. Josephus: the historian and his society, classical life and letters. London: Duckwoth, 1983.

SCHWARTZ, Seth. Josephus and judaean politics. New York: E. J. Brill, 1990.

THACKERAY, Henry St. John. Flavius Josèphe: l'homme et l'historien. Paris: Lês Éditions du Cerf, 2000.

VAN SETERS, John. Em busca da história: historiografia no mundo antigo e as origens da história bíblica. São Paulo: Edusp, 2008.

VIDAL-NAQUET, Pierre. Il buon uso del tradimento: Flavio Guiseppe e la guerra guidaica. Roma: Editori Riuniti, 1980.

VIDAL-NAQUET, Pierre. Os assassinos da memória: "Um Eichmann de papel” e outros ensaios sobre o revisionismo. Campinas: Papirus, 1988.

YERUSHALMI, Yosef Hayim. Zakhor: história judaica e memória judaica. Rio de Janeiro: Imago, 1992.

Recebido: novembro/2009 - Aprovado: abril/2010. 